\title{
Sensitivity of intact and antennule amputated copepods to water disturbance
}

\author{
C. W. Gill* and D. J. Crisp \\ Marine Science Laboratories, Menai Bridge, Gwynedd LL59 5EH, United Kíngdom
}

\begin{abstract}
Behavioural observations were made on restrained individuals of the copepod Temora longicornis Muller, to investigate the range over which sensitivity to water disturbance, in the form of fine jets, could be detected $T$ longiconis was most sensitive to jets in front of it; jets behind were largely disregarded. When placed behind or beside the copepod, positions from which it was less sensitive, the larger or closer the jet, the more frequent was the response. When water flowed in the unnatural postero-anterior direction, the same pattern of sensitivity was shown to disturbances applied at various orientations. Hence propagation of the disturbances was not related to the direction of the water current, nor to its speed. The suspected mechanosensory setae of the antennules are the most likely receptors to be implicated in the detection of fluid disturbances, since amputation of the antennule or antennules greatly reduced the sensitivity of the copepod to jets. Bilateral antennular amputation did not entirely prevent escape responses from being elicited; this indicates there must be mechanoreceptors present on other areas of the body. Furthermore, all areas of the copepod are very sensitive to direct stimulation by water jets.
\end{abstract}

\section{INTRODUCTION}

Swimming copepods create disturbances in the water; these have been visualized by Strickler (1975a, b. 1977) using Schlieren optics. The hydrodynamic disturbance is proportional to the power output of the copepod, and the specific wake patterns are characteristic of the various orders and probably even the individual copepod species. For example, the wake left by calanoids is less distinct than that made by cyclopoids and dissipates about ten times faster (Strickler, 1975a). There is good evidence that plankters can detect water disturbances at a distance and thereby learn to respond to the presence of other organisms whether predator or prey, or even to physical displacement of water (Fleminger and Clutter, 1965; Szlauer, 1965; Drenner et al., 1978; Haury et al., 1980). Carnivorous marine copepods, such as Labidocera trispinosa and Euchaeta elonga, have a well developed vibration sense which orients the copepod towards its swimming prey, although this is preceded by random searching (Lillelund and Lasker, 1971; Landry, 1978; Bailey and Yen, 1983).

\footnotetext{
- Present address: Centre d'Etudes d'Océanographie et de Biologie Marine, CNRS, Station Biologique; F-29211 Roscoff, France
}

Calanoid copepods glide slowly, but make vigorous jerks or leaps when required to escape or attack prey (Lowndes, 1935; Gauld, 1966). In gliding, the cephalic appendages are the chief motor organs which Temora longicornis beats continuously Some copepods, such as Centropages typicus (Cowles and Strickler, 1983) and Cyclops sp. (Storch, 1929; Strickler, 1975a) alternate periods of slow gliding with breaks, during which there is no appendage movement and the copepod is at rest. It has been suggested that the resting phase may be used to orientate to gravity by means of mechanoreceptors on the antennules, and for detection and localization of other sensory inputs from the surrounding medium (Strickler and Bal, 1973; Haury and Weihs, 1976)

At present, it is not known which receptors are responsible for perceiving water movement. Some of the setae on the anterior surface of the antennules have been proposed as mechanoreceptors in 2 species of copepods (Strickler and Bal, 1973; Friedman, 1980). Amputation experiments have been carried out to see if the antennules play an essential role in feeding. Ablation reduced the predation rate in Calanus pacificus but not in Rhincalanus nastus (Mullin and Brooks, 1967; Landry, 1980)

The experiments described below were carried out to investigate the range over which sensitivity to water 
disturbance could be detected, by recording the various responses given by restrained individuals of $\mathrm{Te}$ mora longicornis. Disturbance was provided in the form of fine water jets. The effect of removing one or both antennules on the response was used to investigate the site of the sense organs.

\section{METHODS}

Copepods were collected from the Menai Strait, Gwynedd in a medium mesh plankton net. Temora longicornis, of which only females were available, were isolated and maintained in glass jars of finefiltered, uv irradiated seawater. The copepods were fed a mixture of flagellates and diatoms, and given a minimum of $3 \mathrm{~d}$ to acclimatize to the experimental temperature of $10^{\circ} \mathrm{C}$.

The observations described were obtained from copepods which were restrained in the centre of a perspex flow chamber using an adaptation of the suction electrode used in electrophysiology (see Yule and Crisp, 1983 for details). A narrow size range of nonovigerous female copepods were used. The copepods were attached horizontally, with the antennules at the same level as the body, facing into a gentle seawater flow of $0.17 \mathrm{~cm} \mathrm{~s}^{-1}$. The flow chamber was supplied with seawater from a circulating seawater system which also regulated the water temperature.

Range of sensitivity of intact and operated copepods. The immediate area around a copepod was divided into 8 sectors each $45^{\circ}$ apart with 6 annular zones of $0.075 \mathrm{~cm}$ width at increasing distances from the copepod up to 3 body lengths away. This pattern was drawn on an eyepiece graticule and fitted into a binocular microscope. Each copepod was restrained in the centre of this image.

A fine bore plastic tube was used to direct water jets around or at copepods. One end of the tube was joined to the syringe of a Agla microdoser and the free end was drawn to a fine tip of $70 \mu \mathrm{m}$ diamter and held in a micromanipulator to position it accurately in relation to the copepod. The seawater jets were made just visible by incorporating prefiltered methyl blue, and the weak concentration of dye used did not alter the copepod's behaviour The jets were delivered vertically, from a height of $1.0 \mathrm{~cm}$ above the plane of the copepod. Pulses of 2 strengths were given, the initial muzzle velocity of the strong $\left(6 \mathrm{~cm} \mathrm{~s}^{-1}\right)$ being 4 times that of the weak $\left(1.5 \mathrm{~cm} \mathrm{~s}^{-1}\right)$. Copepod cruising speeds range from 0.09 to $6.0 \mathrm{~cm} \mathrm{~s}^{-1}$ (Hardy and Bainbridge, 1954; Strickler, 1975a; Kerfoot, 1978; Shuvayev, 1978), so the velocities of the water jets were within this range. The jets had slightly less than $2 \mathrm{~cm}$ to travel to the bottom of the chamber where they spread over the base, and were then gradually carried downstream in the minimal flow of $0.17 \mathrm{~cm} \mathrm{~s}^{-1}$.

The copepod was habituated in the restrained position for a minimum of 45 min prior to experiments. Two jets were delivered at each point for each copepod with a minimum of a $15 \mathrm{~s}$ interval, and any subsequent changes in behaviour noted. Observations were made on 15 copepods for each type of water jet, except that when flow was in a postero-anterior direction, 8 copepods were tested. In amputation experiments, the antennule was severed at the junction of the first and second segment with a sharp scalpel. It would also have been possible to remove the caudal rami, but additional experiments (Gill, in prep.) showed that only the antennules were sensitive to mechanical stimulation with a fine hair.

Stimulation of different areas. Fine water jets were directed at various areas of Temora longicornis from a distance of $1.0 \mathrm{~cm}$ using the apparatus described above. Five copepods were tested and 5 jets were given per area. The areas stimulated were: caudal rami, urosome, metasome, cephalosome and antennules. Responses were recorded during and immediately after a short pulse of seawater, which was the same velocity as the weak jets above $\left(1.5 \mathrm{~cm} \mathrm{~s}^{-1}\right)$. To determine any directionality of response, the jets were directed to impinge from several directions.

Changes in behaviour recorded. (a) Flicking only the tip of a single antennule; (b) flicking both antennules but not the legs or tail; the antennules were flattened back alongside the body; (c) flicking the tail alone; (d) flicking legs and tail, but not the antennules; $\left(e_{i}\right)$ single escape response: rapid flick of antennules back alongside the body, kicking the legs backwards, and flicking the urosome (tail) upwards; $\left(e_{11}\right)$ single flick of antennules with repeated flicks of legs and tail; (f) repeated escape responses; ( $g$ ) antennules were bent backwards and held alongside the body, while legs and tail were rapidly and repeatedly flicked.

Fig. 1. Temora longicornis. Percentages of copepods responding to weak water jets with any change in behaviour The immediate area around a copepod was divided into 6 annular zones of $0.075 \mathrm{~cm}$ width, and 8 sectors, each $45^{\circ}$ apart. $\mathrm{AR}=$ anterior right; $\mathrm{ALR}=$ anterior lateral right; $\mathrm{PLR}=$ posterior lateral right; $\mathrm{PR}=$ posterior right; $\mathrm{PL}=$ posterior left; $\mathrm{PLL}=$ posterior lateral left; $\mathrm{ALL}=$ anterior lateral left; $\mathrm{AL}=$ anterior left. (2) Percentages of copepods responding to weak water jets with escape responses; (3) percentages responding to strong water jets; (4) percentages responding to weak water jets after the left antennule had been removed; (5) percentages responding to weak water jets after both antennules had been removed. (6) percentages responding to strong water jets after both antennules had been removed; (7) percentages responding to weak water jets with posteroanterior flow 

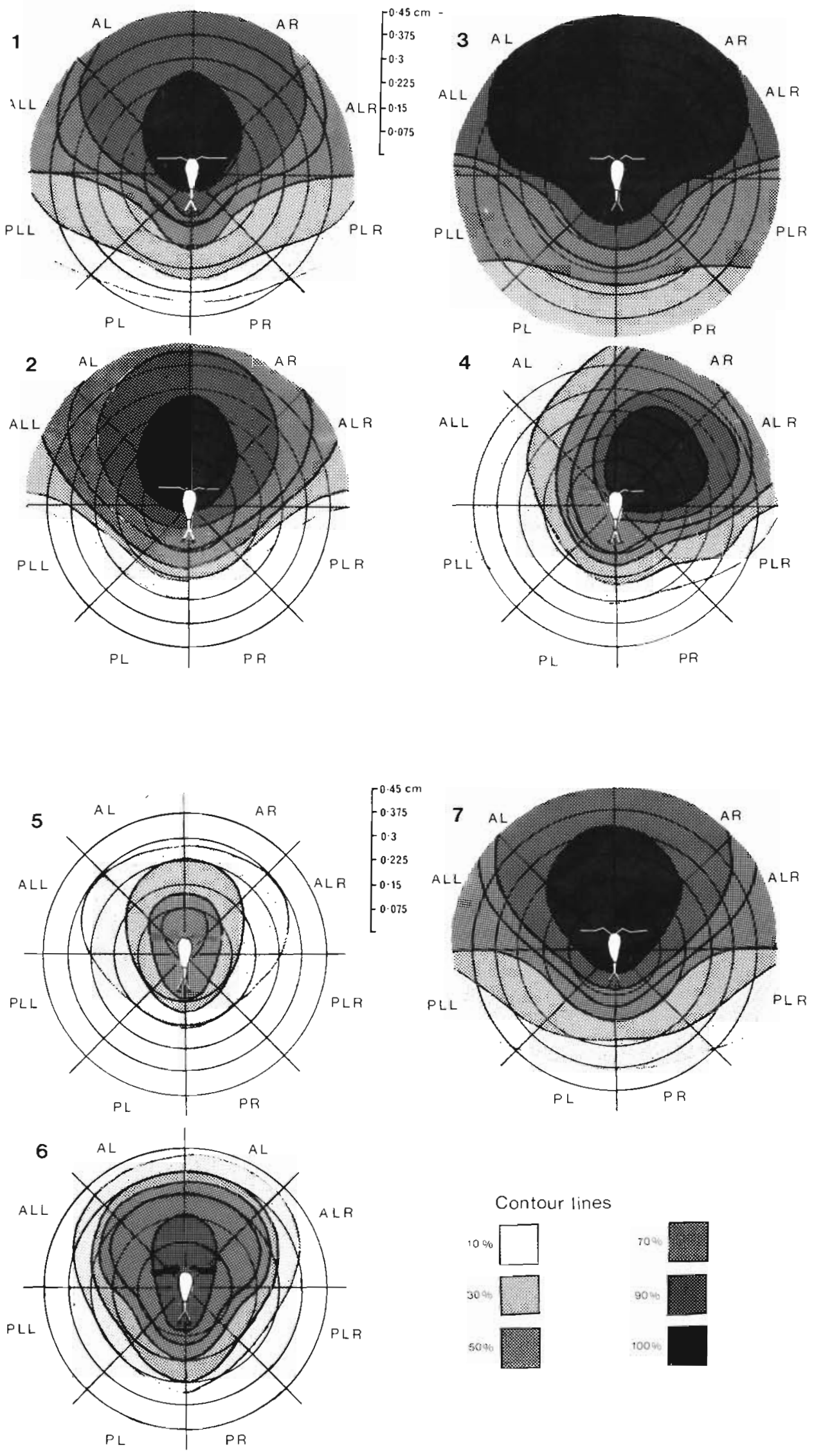


\section{RESULTS}

\section{Stimulation by weak water jets}

Fig. 1,1 maps the mean percentage of copepod trials in relation to distance and orientation about a restrained individual, in which all responses to jets were recorded. The shaded areas, representing contours of response, are plotted at 100, 90, 70, 50, 30 and $10 \%$ levels. Similar representations are given in Fig. 1,2 to 7 for other forms of stimulation. The figure shows that the largest area of sensitivity to weak jets lies in front of the copepod. Since jets behind the copepod are largely disregarded, the contour lines of sensitivity rapidly attenuate in this region.

By far the commonest reaction to any water jet and particularly those to the front of the copepod, was an escape response. The percentage sensitivity contours of escape responses to weak water jets are shown in Fig. 1,2. Under 'escape response' we include flicking the legs and tail but not the antennules, since the former has the effect of helping the copepod to escape (see 'Methods'). There were a few occasions when a copepod flicked a single antennule or the tail alone. As Fig. 1,2 closely resembles Fig. 1,1, subsequent figures include all responses (see 'Methods', a to g).

\section{Stimulation by strong water jets}

Results presented in Fig. 1,3 are essentially the same, except for the greater proportion of responses extending to greater distances as expected. When strong jets were applied Temora longicornis usually gave an escape response, the strongest possible reaction. Only occasionally were the legs and tail flicked without moving the antennules, and only in response to water jets more than $0.15 \mathrm{~cm}$ to the rear of the copepod.

\section{Stimulation by weak water jets with the left antennule removed}

All the responses shown by Temora longicornis are iilustrated in Fig. 1, 4, in which only one, the right antennule could respond. The right hand side of the diagram shows that the side of the copepod retaining its antennule responded to weak water jets directed in front of the remaining antennule (Sectors AR, ALR, as explained in legend to Fig. 1), to the same extent as intact individuals illustrated in Fig. 1,1. However when the jets were similarly directed on the left side and the antennule had been amputated (Sectors AL, ALL) the response was greatly reduced giving an asymmetric contour pattern. There was a similar asym- metry in response to water jets directly behind the amputated antennule (Sector PLL). As before, the most common reaction was an escape response with only occasional flicking of the remaining antennule alone the tail, or the legs and tail alone.

\section{Stimulation by weak water jets with both antennules removed}

Fig. 1,5 clearly shows that removal of both antennules greatly reduced the response, so that to cause any effect in behaviour the water jets must be placed much closer (cf Fig. 1,1 to the same scale). Temora longicornis still responded to weak water jets directed at a maximum distance of $0.300 \mathrm{~cm}$ to the front and $0.225 \mathrm{~cm}$ to the rear. Once both antennules had been removed the copepod could only signal a response by flicking the legs, or tail, or both, or by interrupting the limb beat. The copepods most frequently responded by flicking the legs and tail repeatedly. Their inability to give an antennulary response did not prevent escape responses being elicited.

\section{Stimulation by strong water jets with both antennules removed}

After both antennules had been removed, increasing the strength of the jets only slightly increased the distance to which Temora longicornis could respond (Fig. 1,6) in comparison to weak water jets. Flicking of the legs and tail was similarly the most frequent response. In comparison with an intact copepod, the removal of a single antennule decreased the proportion of tail flicking, whereas the removal of both antennules increased the number of times the tail alone was flicked.

Stimulation by weak water jets with postero-anterior flow

This was done to establish whether the copepods were responding to small eddies from the jets, which were carried past the copepod in the direction of flow. There was no greater sensitivity at the rear when flow was reversed (Fig. 1, $)$ ), and the results are essentially the same as those given for weak water jets with flow in an antero-posterior direction, as shown in Fig. 1.

\section{Stimulation of different areas}

All areas of Temora longicornis were very sensitive to direct stimulation by water jets, as shown in Table 1 , 
Table 1. Temora longicornis. Percentages of the various responses to water jets (abbreviations explained in 'Methods')

\begin{tabular}{|lcccc|}
\hline \multicolumn{1}{|c}{ Area } & \multicolumn{5}{c|}{$\begin{array}{c}\text { Total percentages of different responses } \\
\end{array}$} & $\left(\mathrm{e}_{\mathrm{i}}\right)$ & $\left(\mathrm{e}_{\mathrm{H}}\right)$ & $(\mathrm{f})$ & $(\mathrm{g})$ \\
\hline Caudal rami & & 95.2 & & 4.0 \\
Urosome & & 97.6 & & 3.2 \\
Metasome & 60.0 & 38.4 & 1.6 & \\
Cephalosome & & & & 100 \\
Antennules & & & & 100 \\
\hline
\end{tabular}

the responses being of the magnitude of a single escape response, $\left(e_{1}\right)$, or greater. The most sensitive areas were at the anterior of the copepod - the cephalosome and antennules. Jets to these areas always resulted in the strongest reaction possible $(\mathrm{g})$. The direction of jet impingement caused no difference in response.

\section{DISCUSSION}

\section{Possible stimuli of the observed responses}

Temora longicornis does not have image-forming eyes (Elofsson 1971). Furthermore the ability of copepods to avoid each other, a pipette or a net has been shown to be independent of illumination, indeed copepods attack fish larvae swimming in the dark (Strickler, 1970; Singerajah, 1975; Bailey and Yen. 1983). Whilst chemoreception probably ensures mating encounters (Katona, 1973; Griffiths and Frost, 1976; Blades and Youngbluth, 1979, 1980; Jacoby and Youngbluth, 1983), there remains pressure pulses or velocity displacements as candidates for transmitting information concerning fluid motions around the copepod

Temora longicornis is sensitive to pressure changes of about $10 \mathrm{mb}$ (Rice, 1965; Knight-Jones and Morgan, 1966) and could readily sense a pressure pulse, but to sense the direction from which the signal had travelled would require sensing a pressure gradient. Since pressure is a scalar quantity, this would require a battery of mechanoreceptors to follow the propagation of the impact of pressure changes. In contrast, water movement or displacement are vectors and carry information concerning direction, so single sensors responding to displacements could provide information on the direction from which it came.

Each mechanosensory seta is triggered by bending. It is possible that increasing and decreasing pressures produce minute compressions of the setae. Bending will also take place whenever the relative velocity of flow past the distal end is sufficient to transfer the necessary momentum. Because sensors are distributed in several directions around the body and antennules, they can potentially give information on the pressure or velocity gradients in the surrounding medium (Friedman, 1980).

If responses were mediated by transient disturbances in flow pattern when the current was anteroposterior, Temora longicornis would receive information from in front. The pattern of sensitivity shown in Fig. 1,1 to 6 woud result from disturbances being carried past the copepod, whereas disturbances generated by jets from behind would be carried away and not sensed. However, when water flowed in the unnatural postero-anterior direction, the copepod's response remained the same (Fig. 1,7). Therefore, propagation of the disturbance was not related to the direction of the water current nor to its speed.

The velocity of a water jet decreases rapidly with distance. The above-mentioned experiments deal with $1 \mathrm{~s}$ transient jets which will take a significant time to reach the copepod. Since Temora longicornis reacted instantaneously to these jets it is probably the accompanying pressure pulse that causes the responses, as the pressure pulse will travel at the speed of sound in water $\left(1500 \mathrm{~m} \mathrm{~s}^{-1}\right)$.

\section{Response to fine water jets}

Kerfoot (1978) found that Cyclops sp. detected prey at a distance of 2 to 3 body lengths, although most attacks took place within a single body length. The larger copepod Calanus finmarchicus could detect obstacles at a distance of $0.7 \mathrm{~cm}$ (Haury et al., 1980). As Temora longicornis responded to every trial when strong water jets were to the front, the copepods could probably give some response to a disturbance more than $0.45 \mathrm{~cm}$ away. In directions from which it was less sensitive, the results show that the larger or closer the jet was offered to $T$. longicomis the more frequent was the response. Therefore, the strength of the stimulus given by strong water jets may be assumed to be analogous to that of large prey, which Calanus sp. and Cyclops sp. were able to detect at a greater distance than small prey (Conover, 1966; Kerfoot, 1978; Landry, 1980). In addition to size, the swimming motion of prey species, such as fish larvae, affected their ease of capture by copepods. Predation rates by the copepod Euchaeta elonga were low on inactive swimmers which create little water disturbance and are relatively undetected (Bailey and Yen, 1983). Predation rates were high on more active swimmers which still had a poorly developed escape response.

The suspected mechanosensory setae of the antennules are the most likely receptors to be implicated in the detection of fluid disturbances, since amputation of 
the antennule or antennules greatly reduced the distance at which copepods responded to the jets. The anterior edge of the antennules of Temora longicornis has a single row of setae (Sars, 1903), some of which have the fine structure of a mechanoreceptor (Gill, 1983). Certain antennulary setae have also been identified as mechanosensory in Cyclops scutifer and in the calanoid Diaptomus pallidus (Strickler and Bal, 1973; Friedman, 1980). Antennule amputation did not prevent escape responses from being elicited, and although to a reduced extent, $T$. longicornis still detected nearby water jets. This indicates there must be mechanoreceptors present on other areas of the body.

Temora longicornis was equally sensitive to jets directed at the antennules from a posterior and an anterior direction, even though the setae only point in an anterior direction. However, it is possible either that the pressure mode was operating, or that the massive degree of stimulation when jets were played directly on the antennules may have overcome any difference in directional sensitivity. Experiments using less powerful stimuli showed that $T$. longicornis was most sensitive to jets directed in front of it, as was Daphnia pulex (Szlauer, 1964). Predatory copepods such as Cyclops sp. and $L$. trispinosa only detect prey in front of them and male copepods follow females, and then seize them from behind (Katona, 1973; Kerfoot, 1978; Landry, 1978). By swimming in the wake of a copepod, the approaching predator or male reduces the possibility of being mechanically detected.

Copepod detection of distant water disturbances promotes an increase in the potential rate of prey capture by increasing the frequency with which prey are encountered. As the size and swimming movements of prey species influences their probability of being captured by copepods (Lillelund and Lasker, 1971; Bailey and Yen, 1983), prey selection appears to be a behavioural process under sensory control.

Temora longicornis was less sensitive to jets directed behind it, even when the flow direction was reversed. However copepods did respond to nearby water jets up to approximately $0.15 \mathrm{~cm}$ to the rear, and were very sensitive to water jets played directly on the urosome and caudal rami. Possibly the sensitivity of the urosome is due to indirect stimulation of the long fine setae on the inner edge of each caudal ramus (Gill, 1983). The reduced response to jets directed at the metasome (Table 1) may also have been due to indirect stimulation of the antennules and caudal rami. It is also possible that some of the occasional setae on the metasome are mechanosensory since $T$. longicornis was still capable of responding to water jets directed around it after both antennules has been removed, but the caudal rami left intact.
The thoracic legs are responsible for most of the thrust that produced the rapid acceleration typical of the calanoid escape response. It is unlikely that the legs give direction to the movement as each pair of legs is joined by a coupler at its base, so contraction of the muscles on one side of the copepod inevitably causes the legs of both sides to kick backwards (Lowe, 1935; Marshall and Orr, 1955; Park, 1966). We have never observed Temora longicornis kick with the legs alone, although Acartia clausi and Centropages typicus use the thoracic legs to supplement the movement of the 2nd maxillae in feeding (Rosenberg, 1980; Cowles and Strickler, 1983). T. longicornis probably uses the tail as a rudder, and the flick of a single antennule may also help to turn the copepod away from a stimulus.

Acknowledgements. C. W. Gill was supported by a grant from the Natural Environment Research Council. We are grateful to R. P. Harris for useful comments.

\section{LITERATURE CITED}

Bailey, K. M., Yen, J. (1983). Predation by a carnivorous marine copepod Euchaeta elonga, on eggs and larvae of the Pacific hake Merluccius productus. J. Plankton Res. 5: 71-82

Blades, P. I., Yongbluth, M. J. (1979). Mating behaviour of Labidocera aestiva (Copepoda: Calanoida). Mar. Biol. 51: 339-356

Blades, P. I., Youngbluth, M. J. (1980). Morphological, physiological and behavioural aspects of mating in calanoid copepods. In: Kerfoot, W. C. (ed.) Evolution and ecology of zooplankton communities. University Press of New England, Hanover, p. 39-51

Conover, R. J. (1966). Feeding on large particles by Calanus hyperboreus. In: Barnes, H. (ed.) Some contempory studies in marine science. Allen and Unwin, London, p. 187-194

Cowles, T. J., Strickler, J. R. (1983). Characterization of feeding activity patterns in the planktonic copepod Centropages typicus under various food concentrations. Limnol. Oceanogr. 28: 106-115

Drenner, R. W., Strickler, J. R., O'Brien, W. J. (1978). Capture probability: the role of zooplankter escape in the selective feeding of planktiverous fish. J. Fish. Res. Bd Can. 35: $1370-1373$

Elofsson, R. (1971). The ultrastructure of a chemoreceptor organ in the head of copepod crustaceans. Acta. zool., Stockh., 52: 299-315

Fleminger, A., Clutter, R. I. (1965). Avoidance of towed nets by zooplankton. Limnol. Oceanogr 10: 96-104

Friedman, M. M. (1980). Comparative morphology and functional significance of copepod receptors and oral structures. In: Kerfoot, W C. (ed.) Evolution and ecology of zooplankton communities. University Press of New England, Hanover, p. 185-197

Gauld, D. T (1966). The swimming and feeding of planktonic copepods. In: Barnes, H. (ed.) Some contemporary studies in marine science. Allen and Unwin, London, p. 313-334

Gill, C. W. (1983). The swimming responses of planktonic organisms, particularly Temora longicornis Müller. Ph. D. thesis, University College of North Wales, Bangor 
Griffiths, A. M., Frost, B. W. (1976). Chemical communication in the marine planktonic copepods Calanus pacificus and Pseudocalanus specificus. Crustaceana 30: 1-8

Hardy, A. C., Bainbridge, R. (1954). Experimental observations on the vertical migration of planktonic animals. J. mar. biol. Ass. U.K. 33: 409-448

Haury, L. R., Weihs, D. (1976). Energetically efficient swimming behaviour of negatively buoyant zooplankton. Limnol. Oceanogr 21: 797-803

Haury, L. R., Kenyon, D. E., Brooks, J. R. (1980). Experimental evaluation of the avoidance reaction of Calanus finmarchicus. J. Plankton Res. 2: 187-202

Jacoby, C. A., Youngbluth, M. J. (1983). Mating behaviour in three species of Pseudodiaptomus (Copepoda: Crustacea). Mar. Biol. 76: 77-86

Katona, S. K. (1973). Evidence for sex pheromones in planktonic copepods. Limnol. Oceanogr. 18: 574-583

Kerfoot, W. C. (1978). Combat between predatory copepods: Cyclops, Epischura \& Bosmina. Limnol. Oceanogr. 23 1089-1102

Knight-Jones, E. W., Morgan, E. (1966). Responses of marine animals to changes in hydrostatic pressure. Oceanogr. mar. Biol. A. Rev. 4: 217-299

Landry, M. R. (1978). Predatory feeding behaviour of a marine copepod, Labidocera trispinosa. Limnol. Oceanogr. 23: $1103-1113$

Landry, M. R. (1980). Detection of prey by Calanus pacificus: implications of the 1st antennae. Limnol. Oceanogr. 25: $545-549$

Lillelund, K., Lasker, R. (1971). Laboratory studies of predation by marine copepods on fish larvae. Fish. Bull. U.S. 69: 655-667

Lowe, E. (1935). On the anatomy of a marine copepod, Calanus finmarchicus. Trans. R. Soc. Edinb. 58: 561-603

Lowndes, A. G. (1935). The swimming and feeding of certain calanoid copepods. Proc. zool. Soc. Lond. 2: 687-715

Marshall, S. M., Orr, A. P. (1955). The biology of a marine copepod. Oliver and Boyd, Edinburgh

Mullin, M. M., Brooks, E. R. (1967). Laboratory culture, growth rate and feeding behaviour of a planktonic copepod. Limnol. Oceanogr. 12: 657-666

Park, T. S. (1966). The biology of a calanoid copepod, Epilabidocera amphitrites. Cellule 66: 129-251
Rice, A. L. (1965). The orientation of the pressure response of some marine copepods. Symp. Crust. Proc mar. biol. Ass. India 3: $1124-1131$

Rosenberg, G. G. (1980). Filmed observations of filter feeding in the marine planktonic copepod Acartia. Limnol. Oceanogr 25: 738-742

Sars, G. O. (1903). An account of the crustacea of Norway. IV Copepoda: Calanoida. Bergen Museum, Bergen

Shuvayev, Yu. D. (1978). Aspects of the movement of some planktonic copepods. J. Hydrobiol. 14: 32-36

Singerajah, K. V. (1975). Escape reactions of zooplankton: effects of light and turbulence. J. mar biol. Ass. U.K. 55 $627-639$

Storch, O. (1929). Die Schwimmbewegung der Copepoden. Verh. dt. zool. Ges. Zool. Anz. 4 (Suppl.): 118-129

Strickler, J. R. (1970). Uber das Schwimmverhalten von Cyclopoiden bei Verminderungen der Bestrahlungsstärke. Schweiz. Z. Hydrol 32: 150-179

Strickler, J. R. (1975a). Swimming of planktonic Cyclops species (Copepoda: Crustacea): pattern, movements and their control. In: Wu, Y.-T., Brokaw, C. J., Brennen, C. (ed.) Swimming and flying in nature, Vol. 2. Plenum Press, New York، p. 599-613

Strickler, J. R. (1975b). Intra- and inter-specific information flow among planktonic copepods: receptors. Verh. int. Verein. theor. angew. Limnol. 19: 2951-2958

Strickler, J. R. (1977). Observations of swimming performances of planktonic copepods. Limnol. Oceanogr. 22: $165-170$

Strickler, J. R., Bal, A. K. (1973). Setae of the 1st antennae of the copepod Cyclops scutifer: their structure and importance. Proc. natn. Acad. Sci. U.S.A. 70: 2656-2659

Szlauer, R. L. (1964). Reaction of Daphnia to the approach of different objects. Polskie Arch. Hydrobiol. 12: 5-16

Szlauer, R. L. (1965). The refuge ability of plankton animals before models of plankton eating animals. Polskie Arch. Hydrobiol. 13: 89-95

Yule, A. B., Crisp, D. J. (1983). A study of feeding behaviour in Temora longicornis (Müller) (Crustacea: Copepoda). J. exp. mar. Biol. Ecol. 71: 271-282 